\title{
Patterns of Trust and Subjective Well-Being Across Europe: New Insights from Repeated Cross-Sectional Analyses Based on the European Social Survey 2002-2016
}

\author{
Christoph Glatz $^{1}$ (D) $\cdot$ Anja Eder ${ }^{2}$
}

Accepted: 17 October 2019 / Published online: 23 October 2019

(c) The Author(s) 2019

\begin{abstract}
This paper offers elaborate analyses regarding the effects of social- as well as institutional trust as parts of social capital on subjective well-being (SWB) by using data from the European Social Survey, including 36 countries and eight time-points between 2002 and 2016. We analyze (1) The development of trust and SWB on the aggregate level; (2) The effect of trust on SWB on the individual cross-sectional level; and (3) The longitudinal and crosssectional effect of trust on SWB on the aggregate level while considering control variables based on previous research. We observe a weak positive trend regarding social trust as well as SWB over time, but no significant change in institutional trust. However, trends are far from homogeneous across countries. In accordance to previous studies, we find a positive effect of social trust on SWB. This effect holds on the individual cross-sectional level for every participating country, but also on the longitudinal level. In view of institutional trust, we see a positive effect on SWB on the individual and aggregate cross-sectional level, but not over time. Thus, this study particularly sheds new light on this relation, indicating that it's cross-sectional relation is due to confounding variables. Moreover, we observe no relation between economic growth and SWB after controlling for unemployment, but a positive effect of decreasing unemployment and inflation on SWB. Our data suggests that establishing an environment with high social trust across Europe would be rewarded with a happy society.
\end{abstract}

Keywords Subjective well-being · Happiness · Social trust · Institutional trust · Longitudinal $\cdot$ Cross-country comparison

Electronic supplementary material The online version of this article (https://doi.org/10.1007/s1120 5-019-02212-x) contains supplementary material, which is available to authorized users.

Christoph Glatz

christoph.glatz@uni-graz.at

Anja Eder

anja.eder@uni-graz.at

1348 Center for Social Research, University of Graz, Universitätsstraße 15, 8010 Graz, Austria

2 Department of Sociology, University of Graz, Universitätsstraße 15, 8010 Graz, Austria 


\section{Introduction}

One important goal for the society as a whole is to increase happiness and well-being. Until recently, the gross domestic income of a country was considered as the major indicator for a good quality of life (Oishi and Schimmack 2010). This economic view relies on the assumption that higher prosperity automatically leads to higher utility and that all members of society profit from a country's affluence to a similar extent. Today, more and more researchers as well as politicians take a more straightforward path and use subjective indicators, mainly collected through surveys, to measure quality of life (Diener et al. 2015). This approach focuses upon individual's appraisals of their own life. The most prominent indicator for this purpose is subjective well-being (SWB), which is composed of positive affect, the lack of negative affect, happiness and life satisfaction (e.g. Diener et al. 2012). ${ }^{1}$

On the individual level, various key aspects have been identified which promote SWB, like the family status (being married), the state of health, social inclusion (many social contacts), income etc. (Dolan et al. 2008; Puntscher et al. 2015). On the country level, there is still a controversial debate on the 45-year-old Easterlin paradox (1974), on the thesis that an increase in a country's gross domestic product does not increase SWB in the long run. According to the paradox, prosperity gains do not foster happiness once a country has achieved a certain degree of affluence (Easterlin et al. 2010; Easterlin 1974).

In the last decade, there has been growing interest in the relation of trust as part of social capital and SWB. Social capital has proven to be one of the key drivers for high SWB, both on the individual (e.g. Bartolini et al. 2013b; Helliwell and Huang 2011; Helliwell and Putnam 2004) and aggregate level (e.g. Bjørnskov 2008). Originally described as the individual resources that one receives from the possession of a durable network by Bordieu (1986), various scholars contributed different definitions of social capital (e.g. Coleman 2000; Putnam 2001), leading to a vague and abstract perception of this concept (see Bjørnskov and Sønderskov 2013). However, more and more researchers agree on the multidimensional nature of social capital, consisting of at least three distinct dimensions, namely (1) networks (e.g. informal relationships, volunteering, organizational memberships, ...); (2) norms (e.g. shared norms, civic values, ...); and (3) trust (e.g. social trust, institutional trust ...) (e.g. van Oorschot and Arts 2005).

This paper focuses upon on the impact of social as well as institutional trust on SWB from an individual cross-sectional as well as an aggregate cross-sectional and longitudinal perspective considering survey data from 35 European countries and Israel. Social trust, on the one hand, is the touchstone of social capital as it reflects generalized reciprocity. "I'll do this for you now, without expecting anything immediately in return and perhaps without even knowing you, confident that down the road you or someone else will return the favor" (Putnam 2001: 134). The core idea behind this effect is that social trust fosters social cohesion. Social networks among family, friends, colleagues at work and in the neighborhood give people a feeling of security, even to people who themselves are not part of the network; thus "social networks have value" (Helliwell and Putnam 2004: 1436).

Institutional trust on the other hand is conceptually distinct from social trust as it includes trust in governments, political authorities or other social institutions. High institutional trust can also foster SWB as a subjective measure of the quality of regional

\footnotetext{
1 The concept of happiness and life satisfaction though are not identical; survey questions differ from each other and research has shown that the correlation of both aspects varies across countries (Ortiz-Ospina and Roser 2017).
} 
institutions, preventing to feel powerless and helpless within the society (Kroll 2008). From a functionalistic perspective, trust in institutions has an essential complexity reducing effect since individuals delegate responsibility and by this decrease transaction costs (e.g. Benz 2002: 275). Cultural theorists argue that trust in the state can be achieved through "knowing the basic idea or good of an institution" and "its constitutive rules, values, and norms" (Warren 1999: 6-7). If institutions stick to the prevailing norms, make fair promises, prove to be reliable and offer participation, citizens will trust in them. Finally, also trust in institutions might contribute to a feeling of certainty and security that have a positive impact on the quality of life.

Although multiple studies found a robust relation between social as well as institutional trust and SWB on a cross-sectional level, longitudinal country-comparative analyses show ambivalent results and in many cases too small numbers of dates in order to provide meaningful results. In addition, findings from single-case analyses or a small number of countries are hard to generalize. For this reason, we extent previous research to get a deeper understanding about the relationship between trust and SWB. We use the European Social Survey (ESS), which allows analyzing these relations on the individual level but also over time on the aggregate level using eight waves from 2002 to 2016 (2004, 2006, 2008, 2010, 2012 , 2014). In this period, most of the European countries were hit hard by the consequences of the global financial crisis, which lead to an economic downturn, increasing unemployment and sovereign debt crisis. In particular, Southern and Eastern European countries faced far-reaching economic and social losses. Moreover, disenchantment with politics has increased in many western countries (Dalton and Weldon 2005). Against this background, the paper addresses the following research questions:

(1) How did subjective well-being and social as well as institutional trust change in European countries from 2002 to 2016 ?

(2) How does trust affect subjective well-being in Europe in this period from a crosssectional perspective?

(3) How do changes of trust influence shifts in Europeans' subjective well-being?

First, we will briefly introduce a review about previous studies in this research field. We focus on (a) time trends of well-being, social and institutional trust, (b) the cross-sectional relation between trust and SWB and (c) findings from longitudinal analyses. The subsequent section on methods and data describes the European Social Survey and the additional macro-data (e.g. GDP per capita, inflation and unemployment rate) used for our analyses as well as the coding of our variables. The results section starts with the overall change of subjective well-being and social as well as institutional trust, followed by cross-sectional analyses on the impact of trust on SWB and an extensive longitudinal analysis. Additional analyses can be found in the supplementary material. Discussion of the results and conclusions close the paper in the last section.

\subsection{State of Research}

This section deals with the international state of research on (a) time trends of subjective well-being, social and institutional trust, (b) the cross-sectional relation between trust and SWB, and (c) the longitudinal relation between trust and SWB.

(a) Time trends of SWB as well as social and institutional trust 
According to data from the World Values Survey, self-reported happiness has increased in the majority of countries in the last decades, also the Eurobarometer reports long-term trends of rising life satisfaction since the 1970s for European countries (Ortiz-Ospina and Roser 2017). Overall, life satisfaction is highest in the more affluent countries and still rising in most western countries (Veenhoven 2014) as well as in European transition countries (Bartolini et al. 2017).

The development of social as well as institutional trust though is more ambivalent. For the US, there is a sharp decrease in social trust between 1960 and 2000 (Putnam 2001), between 1975 and 2004 (Bartolini et al. 2013a) as well as between 1972 and 2012 (Twenge et al. 2014). The main reason for this decline is rooted in cohort effects, meaning that younger cohorts are in general less trustful than older cohorts (Putnam 2001: 141; Schwadel and Stout 2012). For Europe on the other hand, Sarracino (2012) found a positive trend in Sweden, Norway and Denmark, but a negative trend for Great Britain, France, Spain and Ireland between 1980 and 2005. For the time-period of 1990-2012, Sarracino and Mikucka (2017) noticed similar patterns, with a rise in social trust for Scandinavian, Baltic and Western countries, but a decrease in Mediterranean, Anglo-Saxon and many post-communist countries in Eastern Europe. Additionally, Bartolini et al. (2017) examined the development of social trust for European transition countries, and found a positive trend from 2002 to 2008 .

As far as trust in a country's institutions is concerned, Bartolini et al. (2013a) observed a decline for the US between 1975 and 2004, while Sarracino (2012) found a mixed pattern for Australia, Canada, Japan and Western Europe between 1980 and 2005, with increasing trust in the army and police but decreasing trust in the judicial system, religious institutions, the parliament and civil service. Sarracino and Mikucka (2017) obtained similar results for European countries from 1990 to 2012, with a growing trust in public services and armed forces, but decreasing trust in political institutions. Analyses of Eastern European countries show a rather complex pattern, an increase of trust in political institutions shortly after the collapse of communism and again a decrease in the late 1990s (Mishler and Rose 2001: 41f). However, overall scholars state in particular for Eastern Europe that "there is no consistent pattern of change, but rather a lot of fluctuations up and down" (Mishler and Rose 2001: 125).

(b) The impact of trust on subjective well-being across countries

Multiple studies showed a robust relation between social trust and subjective wellbeing in North America (e.g. Helliwell and Putnam 2004), Europe (e.g. Portela et al. 2013; Puntscher et al. 2015; Rodríguez-Pose and von Berlepsch 2014) and all over the world (e.g. Calvo et al. 2012; Helliwell and Putnam 2004; Kroll 2008) on the cross-sectional level. To avoid endogeneity problems in cross-sectional data, multiple studies used instrumental variables and still found a positive effect of social trust on life satisfaction (Growiec and Growiec 2014) and happiness (Koruki 2011).

Besides the prominent role of social trust for a happy live, previous research found a positive effect of institutional trust on SWB in Europe (Hudson 2006; Portela et al. 2013; Puntscher et al. 2015; Rodríguez-Pose and von Berlepsch 2014), Canada (Leung et al. 2011), South America (Macchia and Plagnol 2018) and Russia (Mironova 2015) by using cross-sectional data. Kroll (2008) on the other hand detected no relation between institutional trust and life satisfaction according to data from the World Values Survey for 72 nations worldwide. 
(c) The impact of trust on subjective well-being across countries and time

Since cross-sectional data are prone for omitted confounding variables, several studies used longitudinal data to analyze the relation between the change in social capital and the change in subjective well-being over time. Using this technique, studies showed a positive relation between social trust and subjective well-being in the US (Bjørnskov 2008), in Western European countries (Bartolini and Sarracino 2014), in European transition coun$\operatorname{tries}^{2}$ (Bartolini et al. 2017), in China (Bartolini and Sarracino 2015) and all over the world (Helliwell et al. 2018; Mikucka et al. 2017). Besides social trust, Bartolini et al. (2013a) as well as Helliwell et al. (2018) analyzed the relation between trust in various institutions and SWB. Bartolini et al. (2013a) found a positive effect in the US while Helliwell et al. (2018) discovered a positive effect in Europe. Both studies, however, relied on single items while Bartolini et al. (2013a) only included two time-points.

By analyzing Western countries over time, Sarracino (2010, 2012) found concordant trends in social trust as well as trust in certain institutions and SWB. For Europe, Sarracino (2014) discovered positive trends in social trust and trust in certain institutions, accompanied by a negative trend in SWB. However, these analyses remained on a descriptive level without considering control variables and again relied only on single items to measure institutional trust.

\subsection{This Study}

In order to overcome the weaknesses of previous studies, it is important to analyze the relation between subjective well-being and trust by using as many time points as possible and to limit the analysis on European countries that share a common history and culture. Since most studies rely on data from the US-American General Social Survey (GSS) and the World Values Survey (WVS), we introduce the European Social Survey (ESS) to replicate and extend previous research in this field. Using this survey, Bünger (2010) found a positive relation between social inclusion and life satisfaction whereas Hooghe and Vanhoutte (2011), Lopes et al. (2014), Portela et al. (2013) as well as Rodríguez-Pose and von Berlepsch (2014) discovered a positive relation between social capital and subjective wellbeing on the cross-sectional level.

Three studies used the ESS for longitudinal analysis, examining the relation between social trust and SWB for Europe as a whole (Helliwell et al. 2018; Bartolini and Sarracino 2014) and European transition countries only (Bartolini et al. 2017). Although those studies substantially contributed important insights, they did not account for control variables except GDP growth nor examined the relation between institutional trust (as one unique factor) and SWB. With the exception of Mikucka et al. (2017) who analyzed the WVS, previous studies using aggregate longitudinal data did not distinguish contextual effects between countries, which result from different levels in trust and subjective well-being, and within effects resulting from the change in trust and subjective well-being, leading to one parameter for two distinct effects (see Bell et al. 2018). Thus, we analyze both effects of social as well as institutional trust on subjective well-being.

2 This relation holds for the medium run (4-6 years) but not for the short run (2 years). 
Table 1 Items from the European social survey questionnaire capturing subjective well-being as well as social and institutional trust

\begin{tabular}{ll}
\hline Items & Construct \\
\hline 1. Taking all things together, how happy would you say you are? & Subjective \\
2. All things considered, how satisfied are you with your life as a whole nowadays? & Well-being \\
3. Generally speaking, would you say that most people can be trusted, or that you can't & Social trust \\
be too careful in dealing with people? & \\
4.Do you think that most people try to take advantage of you if they got the chance, or & \\
would they try to be fair? & \\
5. Would you say that most of the time people are helpful or mostly looking out for & \\
themselves? & \\
Please tell me on a score of $0-10$ how much you personally trust each of the institutions & Institutional trust \\
I read out. Firstly... & \\
1.... Country]'s parliament? & \\
2....The legal system? & \\
3....Politicians? & \\
4....The European Parliament? & \\
5....The United Nations? & \\
...The police (excluded due to low factor loading) &
\end{tabular}

\section{Method}

For our study, we use the European Social Survey (ESS). The ESS is conducted every 2 years via face-to-face interviews and consists of a core module and a rotating module, which varies every 2 years. In the first round, which took place in 2002, 22 countries participated in the ESS. Fifteen took part in every round since then; four more skipped not more than one round. A total of 36 countries conducted the survey at least once with two more countries (Montenegro and Serbia) following in 2018. In total, the ESS dataset consists of 393.495 individuals nested in 36 countries and eight time-points. The core module of the ESS contains sociodemographic variables as well as items to measure trust and subjective well-being.

\subsection{Subjective Well-Being (SWB)}

Subjective well-being consists of an affective and a cognitive aspect whereas affective components are captured in the measurement of happiness while life satisfaction provides information about the cognitive component (Diener et al. 2012). The ESS contains one item to measure happiness and one item to measure life satisfaction (see Table 1), both on a 11 point-scale ranging from " 0 " (extremely unhappy/dissatisfied) to "10" (extremely happy/satisfied). Since both questions measure one distinct aspect from the same latent factor (see Diener and Ryan 2009), we compute the mean of both questions as a measure of subjective well-being. The internal consistency of subjective well-being reaches Cronbach's $\alpha=0.83$. We additionally conducted our analysis separately for both items. If these results vary, we mention it as footnotes or note to the table, otherwise the direction and significance are the same for happiness and life satisfaction with similar effect sizes. 


\subsection{Trust}

The ESS contains three questions to measure social trust as well as six items to measure institutional trust which are part in every survey wave (see Table 1). We performed a main axis factor analysis with varimax rotation for every ESS round as well as confirmatory factor analyses for every ESS round separate for each country to investigate the underlying factors. According to explorative factor analysis, the three items to measure social trust form one factor with factor loadings of at least 0.61. The remaining items measuring institutional trust form one distinct factor as well, although the item "trust in the police" yielded low factor loadings at every time point, ranging from 0.55 to 0.67 . After the exclusion of this item factor loadings reached at least 0.64 . In accordance, the findings from confirmatory factor analysis also show a better model fit when excluding "trust in the police". Comparative Fit Index is higher in all countries, although the index reaches the minimum level of 0.9 in most countries also before the exclusion of trust in the police. ${ }^{3}$

\subsection{Control Variables}

We analyze the ESS on the individual as well as on the aggregate level. On the individual level, we control for sex, marriage, age, age square, education, household income, place of residence, unemployment, social contacts, social activities and subjective health. We use dummy variables to measure sex $(1=$ female $)$, marriage $(1=$ married $)$, education (primary education or below, lower secondary education, upper secondary education, post-secondary education non-tertiary education and tertiary education), place of residence (big city, suburbs, town, village, countryside) and unemployment ( $1=$ unemployed). Since the survey question regarding household income changed between the third and fourth ESS round, we use "feeling about household's income nowadays" with a four point likert-scale ranging from " 1 - living comfortably on present income" to "4 - finding it very difficult on present income" as proxy for household income. Social contacts ("How often do you meet socially with friends, relatives or work colleagues?"), social activities ("Compared to other people of your age, how often would you say you take part in social activities?") and subjective health ("How is your health in general?") are all measured with scales from 1 to 5 or 1 to 7. For better comparison, we rescale these items to 0-10 (whereas higher scores represent higher household income, more social contacts and activities and better subjective health).

On the aggregate level, we control for the $\log _{2}$ of GDP per capita in US dollar, the inflation and unemployment rate in \% (source: World Bank). We additionally include the level of income inequality after taxes and transfers in the models by using the Gini coefficient from the Standardized World Income Inequality Database (SWIID; Solt 2019). The SWIID theoretically reaches from 0 to 100 , albeit higher values mean that the incomes are distributed more unequally in a society.

\footnotetext{
3 The factor solution shows some weaknesses in single countries at some time points. Root Mean Square Error of Approximation > 0.05 in France in 2002 and 2004, in Great Britain in 2006, in Sweden in 2002, 2004 and 2006, in Turkey in 2008, and in the Ukraine in 2006, 2008, 2010 and 2012.

Because some countries are members of the European Union and other's not we also calculated models without the item "trust in the European Union". However, the fit of the models was distinctly lower in the vast majority of countries so that we kept the item for the ongoing analyses.
} 


\subsection{Procedure/Model}

To reach the full potential of the dataset, we proceed our statistical analysis in three distinct steps. First, we use a latent growth curve model to analyze the changes of subjective well-being and trust in Europe from 2002 to 2016. Subsequently, we analyze the relation between trust and subjective well-being. We start this analysis on the individual level with a pooled cross-sectional multilevel regression analysis including all eight waves from the ESS. As a last step, we use a repeated cross-sectional design to analyze the longitudinal as well as cross-sectional relation between trust and subjective wellbeing on the aggregate level (see Fairbrother 2014).

Since micro- and macroeconomic predictors show different effects on SWB for less developed transition countries compared to developed countries (Bartolini et al. 2017; Howell and Howell 2008; Nikolova 2016; Rodríguez-Pose and von Berlepsch 2014) despite different SWB levels per se (Ortiz-Ospina and Roser 2017), we additionally conducted separate analyses for developed and former socialist transition countries. The country group "developed countries" includes Switzerland, Denmark, Finland, Great Britain, Ireland, Spain, Portugal, Italy, Cyprus, Luxembourg, Iceland, Netherland, Norway, Sweden, Austria, Belgium, France, Germany, Greece and Israel. "Transition countries” include Slovenia, Albania, Bulgaria, Romania, Russia, Slovakia, Turkey, Ukraine, Kosovo, Croatia, Hungary, Poland, Czech Republic, Estonia, Lithuania and Latvia.

For descriptive statistics as well as the latent growth curve models, we only include countries with at least seven time-points since the trends would be distorted otherwise. This resulted in a total of 19 countries (Austria, Belgium, Switzerland, Czech Republic, Germany, Denmark, Estonia, Spain, Finland, France, Great Britain, Hungary, Ireland, Netherlands, Norway, Poland, Portugal, Sweden, and Slovenia), leading to a total of 148 observations. Since this sample only includes five transition countries, we do not differentiate between country groups.

For the repeated cross-sectional design, we rely on the "within-between random effects" model as described by Bell and Jones (2015) and Bell et al. (2018). This model allows examining the relation between trust and subjective well-being in two different ways. First, we can estimate how the change in trust over time relates to subjective wellbeing across countries. Second, we can estimate the contextual effect of trust on subjective well-being by examining the relation for the mean score in trust across all timepoints for each country with subjective well-being.

Since omitting random effects could lead to biased results in our multilevel models (Bell et al. 2018) but including all parameters could result in overfitting (Hawkins 2004), we use goodness of fit indicators (AIC, BIC) to compare different models which include different random effects (intercepts and slopes) as proposed by Hox et al. (2017: 38). In this stage, we do not use restricted maximum likelihood estimation (REML) since it would not allow for model comparison. However, REML provides robust parameter estimations for multilevel modelling (Hox et al. 2017: 28) which is why we re-run our final models (including the suggested random effects by our goodness-of-fit indicators) and present them with REML estimations. To estimate explained variance in the models, we use marginal $\mathrm{R}^{2}$ and conditional $\mathrm{R}^{2}$ as proposed by Nakagawa and Schielzeth (2013). While marginal $R^{2}$ reflects explained variance by fixed factors, conditional $R^{2}$ reflects explained variance by the entire model (fixed + random effects). 


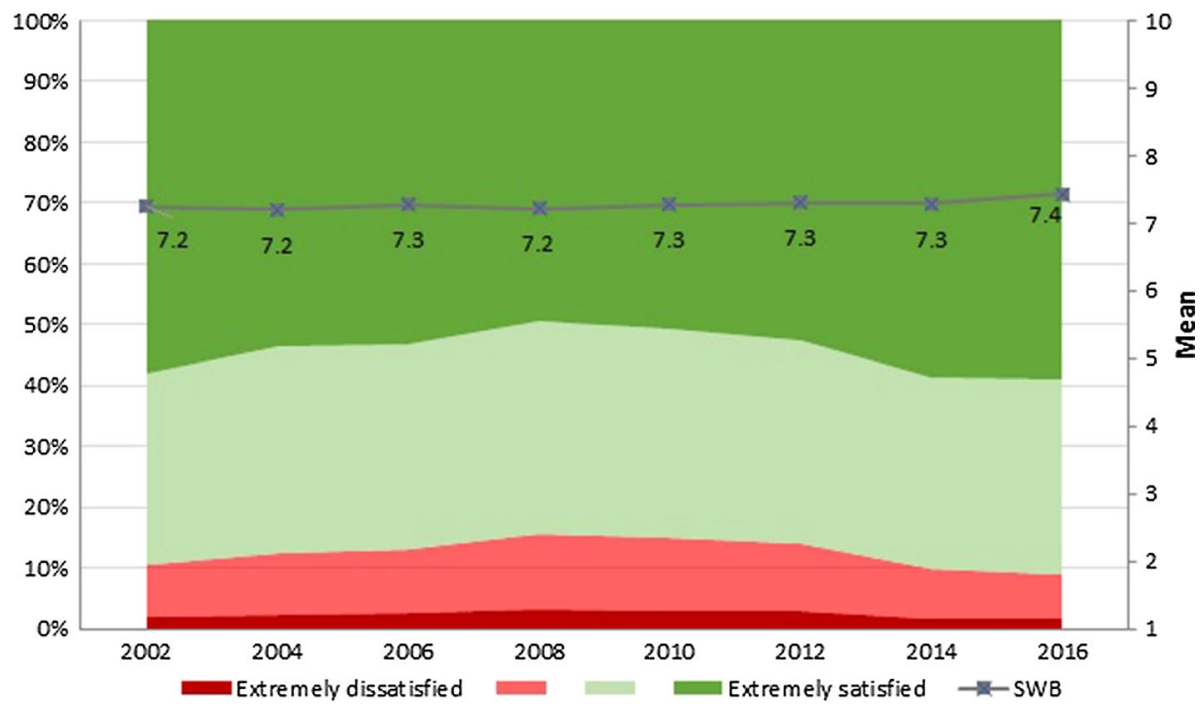

Fig. 1 Trends of subjective well-being from 2002 to 2016 across 19 European countries. The four categories are derived from the mean-index scaled from 0 to 10 , albeit "extremely dissatisfied" reaches from 0 to 2, "dissatisfied" from 2.5 to 4.5 , "satisfied" from 5 to 7 and "extremely satisfied" from 7.5 to 10

\section{Results}

We start our analyses with a descriptive overview of the trends of subjective well-being as well as social and institutional trust in the selected European countries and Israel. With a mean of 7.2-7.4, Fig. 1 shows high levels of subjective well-being across European countries and on average a positive trend from 2002 to 2016. In 2002, 89\% of the Europeans are satisfied or extremely satisfied with their lives; in 2008 we can find the lowest level of satisfaction with $84 \%$ and in 2016 the highest level of satisfaction with $91 \%$.

Figure 2 illustrates the changes of the central independent variables of social and institutional trust. With means of 4.6-5.5, average social and institutional trust are distinctly lower than subjective well-being, albeit trust in others is more pronounced across Europe than trust in various institutions. Taking into account the changes of social trust from 2002 to 2016, a positive linear trend is obvious, the mean increases from 5.3 to 5.5. In contrast, institutional trust slightly decreases from 4.8 to 4.7 in this period and does not show a clear pattern, since it is lowest from 2010 to 2014 but also in 2004. Overall, subjective wellbeing as well as social and institutional trust though are rather stable across time, showing only minor changes from 2002 to 2016 on average.

After depicting our descriptive data, we continue with the latent growth curve models, examining how SWB and trust developed in Europe from 2002 to 2016 (see Table 2). We analyzed the data both with a linear as well as with a quadratic time term. For the quadratic effect, we use the orthogonal rather than the natural quadratic term to avoid a correlation between the linear and quadratic time effect (see Mirman 2014). After the comparison of different models with different goodness-of-fit indices, we included linear random slopes in addition to random intercepts. Since we use the orthogonal rather than the natural quadratic effect, we can interpret the intercepts as a mean across all time points (Mirman 2014). 
10

9

8

7

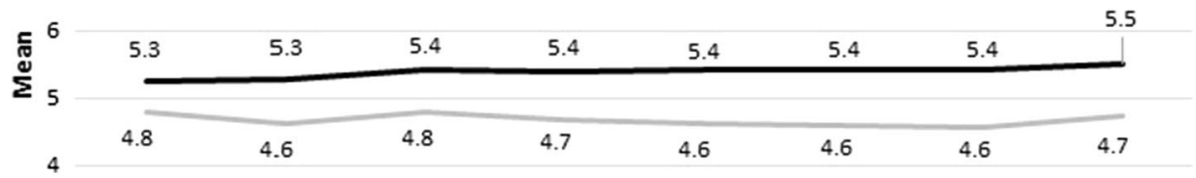

3

2

1

$\begin{array}{llllllll}2002 & 2004 & 2006 & 2008 & 2010 & 2012 & 2014 & 2016\end{array}$

Fig. 2 Trends of social and institutional trust between 2002 and 2016 across 19 European countries

Table 2 Development of subjective well-being and trust from 2002 to 2016 across 19 European countries (latent growth curve models)

\begin{tabular}{|c|c|c|c|c|c|c|}
\hline & \multicolumn{2}{|c|}{ Subjective well-being } & \multicolumn{2}{|l|}{ Social trust } & \multicolumn{2}{|c|}{ Institutional trust } \\
\hline & Estimate & SE & Estimate & SE & Estimate & SE \\
\hline Intercept & $7.27 * *$ & 0.15 & $5.39 * * *$ & 0.18 & $4.67 * * *$ & 0.18 \\
\hline Linear & $0.15^{*}$ & 0.08 & $0.20 * * *$ & 0.04 & -0.12 & 0.11 \\
\hline Quadratic & -0.05 & 0.04 & $-0.12 * * *$ & 0.03 & -0.03 & 0.05 \\
\hline Observations & 148 & & 148 & & 148 & \\
\hline$\sigma^{2}$ & 0.03 & & 0.02 & & 0.05 & \\
\hline Random intercepts & 0.40 & & 0.63 & & 0.60 & \\
\hline Random slopes-linear & 0.09 & & 0.02 & & 0.17 & \\
\hline AIC & 15.6 & & -54.4 & & 103.8 & \\
\hline BIC & 36.5 & & -33.5 & & 124.8 & \\
\hline Df & 7 & & 7 & & 7 & \\
\hline Marginal $\mathrm{R}^{2} /$ conditional $\mathrm{R}^{2}$ & $0.8 \% / 93.8 \%$ & & $1.0 \% / 97.4 \%$ & & $0.3 \% / 91.9 \%$ & \\
\hline
\end{tabular}

After the comparison of different models with different goodness-of-fit indices (AIC, BIC), we included random linear slopes in addition to random intercepts. $* p<0.05, * * p<0.01, * * * p<0.001$

Corresponding to the descriptive results the mean level of SWB is 7.3 on a $0-10$ scale and thus higher than those of social- and institutional trust with means of 5.4 and 4.7 (see Table 2). SWB shows a positive linear trend, ${ }^{4}$ however, the variation between countries is quite large. Nevertheless, despite Ireland (where SWB shows a negative trend), Germany

${ }_{4}^{4}$ We obtain the same result for life satisfaction, but no significant increase in happiness. 
and Poland (where we see a significantly higher increase in subjective well-being compared to the fixed effect and thus all countries combined), all remaining countries show coefficients which do not differ significantly from the reported fixed effect of 0.15 . This result is in accordance to the findings of Alessi et al. (2018), who showed that Germany and Poland suffered the least from the economic crisis while Greece, Ireland, Latvia, and Croatia suffered the most. Unfortunately, our dataset only contains four time-points for Greece $\left(02^{\prime}, 04^{\prime}, 08^{\prime}, 10^{\prime}\right)$, two for Latvia $\left(06^{\prime}, 08^{\prime}\right)$ and two for Croatia $\left(08^{\prime}, 10^{\prime}\right)$ which are not part of the latent growth curve model (see method section). During the economic crisis, we see a distinct drop of SWB in Greece of -0.2 points from 2004 to 2008 resp. -0.7 points from 2004 to 2010. In Latvia, we observe a small decrease of -0.1 points in SWB from 2006 to 2008 and Croatia shows a drop of -0.25 points from 2008 to 2010 .

While social trust shows a significant positive linear trend, institutional trust does not vary across time. A close look on different countries reveals that institutional trust shows a positive trend in Norway and Sweden but a negative trend in Spain, Slovenia and Portugal. Overall, as indicated by the random slopes, the development of institutional trust across Europe is far from homogenous and strongly varies across different countries. If we take a closer look on the countries which are most affected by the economic crisis in terms of SWB loss (Alessi et al. 2018), we see no decline of social trust in Greece, Latvia, and Croatia, but a drop of approximately -0.3 points in Ireland from 2008 to 2010. All four countries, however, show a clear decrease in institutional trust during this period. In Greece, institutional trust drops -0.8 points from 2004 to 2008 , and -2.1 points from 2004 to 2010. In Latvia and Ireland, we see a decrease of -0.4 points from 2006 to 2008 while Croatia shows a decline of -0.3 points from 2008 to 2010 . Differences across countries regarding trends in SWB and trust are depicted in the Figures A1 to A3 in the supplementary material.

We continue with the analysis regarding the relation between SWB and trust. At the beginning, we use multilevel modelling to analyze the individual cross-sectional relation between trust, our control variables and SWB by means of a pooled dataset including all eight time-points of the ESS. Besides individual trust, we include aggregate trust for every country and time-point as predictor variables to our models. We include random slopes (between countries) for both trust variables in addition to random intercepts for countries and ESS time-points. Moreover, we run separate models for developed countries and post socialist transition countries (see Table 3). For the whole dataset, $18.2 \%$ of the variation in SWB is due to differences across countries as described by the intraclass correlation (ICC). This variation is higher in developed countries (10.5\%) compared to former socialist transition countries $(6.1 \%)$. Overall, our model explains $40.5 \%$ of variance whereas our fixed effects explain $37.7 \%$.

Regarding our control variables, many social contacts, high subjective health and high household income are positively related with high SWB. Moreover, female, employed and married respondents report higher SWB. Age on the other hand is negatively related to SWB whereas age square is positively related, indicating a u-shaped relation. Higher education shows a small positive effect on SWB in transition countries, but a small negative effect in developed countries. Regarding our variables of interest, individual social and institutional trust are positively related to SWB, in the whole sample as well as in transition and developed countries. Moreover, aggregate social trust shows a particular high relation with individual SWB compared to individual social trust, whereas aggregate institutional trust shows a small negative, non-substantial relation with SWB.

Since we included random slopes for social as well as institutional trust in our model, it is possible to analyze if the impact of individual social and institutional trust on SWB 
Table 3 The impact of social and institutional trust on subjective well-being (multilevel models)

\begin{tabular}{|c|c|c|c|c|c|c|}
\hline \multirow[t]{2}{*}{ Outcome Variable:Subjective well-being } & \multicolumn{2}{|l|}{ All countries } & \multicolumn{2}{|c|}{ Transition countries } & \multicolumn{2}{|c|}{ Developed countries } \\
\hline & Estimate & SE & Estimate & SE & Estimate & SE \\
\hline Intercept & 1.12 & 0.14 & 1.34 & 0.21 & 0.79 & 0.66 \\
\hline Individual social trust & 0.14 & 0.01 & 0.14 & 0.01 & 0.14 & 0.01 \\
\hline Individual institutional trust & 0.11 & 0.01 & 0.16 & 0.01 & 0.07 & 0.01 \\
\hline Aggregate social trust & 0.36 & 0.02 & 0.26 & 0.04 & 0.43 & 0.02 \\
\hline Aggregate institutional trust & -0.05 & 0.01 & -0.10 & 0.02 & -0.02 (ns.) & 0.01 \\
\hline Social contacts & 0.07 & 0.00 & 0.06 & 0.00 & 0.07 & 0.00 \\
\hline Social activities & 0.07 & 0.00 & 0.06 & 0.00 & 0.06 & 0.00 \\
\hline Subjective health & 0.22 & 0.00 & 0.25 & 0.00 & 0.20 & 0.00 \\
\hline Age & -0.04 & 0.00 & -0.05 & 0.00 & -0.03 & 0.00 \\
\hline $\operatorname{Age}^{2}$ & 0.00 & 0.00 & 0.00 & 0.00 & 0.00 & 0.00 \\
\hline Female & 0.14 & 0.01 & 0.21 & 0.01 & 0.11 & 0.01 \\
\hline Married & 0.49 & 0.01 & 0.48 & 0.01 & 0.48 & 0.01 \\
\hline \multicolumn{7}{|l|}{ Primary education or below (baseline) } \\
\hline Lower secondary education & -0.06 & 0.01 & 0.06 & 0.03 & -0.04 & 0.01 \\
\hline Upper secondary education & -0.08 & 0.01 & 0.04 (ns.) & 0.03 & -0.06 & 0.01 \\
\hline Post-secondary education & -0.10 & 0.01 & 0.06 (ns.) & 0.03 & -0.09 & 0.01 \\
\hline Tertiary education & -0.13 & 0.01 & 0.16 & 0.03 & -0.19 & 0.01 \\
\hline Household income & 0.19 & 0.00 & 0.22 & 0.00 & 0.17 & 0.00 \\
\hline Unemployed & -0.43 & 0.01 & -0.43 & 0.02 & -0.43 & 0.01 \\
\hline \multicolumn{7}{|l|}{ City (baseline) } \\
\hline Suburbs & -0.02 (ns.) & 0.01 & -0.01 (ns.) & 0.03 & 0.02 (ns.) & 0.01 \\
\hline Town & 0.01 (ns.) & 0.01 & -0.01 (ns.) & 0.01 & 0.04 & 0.01 \\
\hline Village & 0.06 & 0.01 & 0.00 (ns.) & 0.01 & 0.12 & 0.01 \\
\hline Countryside & 0.16 & 0.01 & -0.11 & 0.05 & 0.21 & 0.01 \\
\hline Observations & 335,122 & & 101,946 & & 233,176 & \\
\hline ICC & $18.2 \%$ & & $6.1 \%$ & & $10.5 \%$ & \\
\hline$\sigma^{2}$ & 2.45 & & 3.03 & & 2.17 & \\
\hline Random Intercepts & 0.33 & & 0.20 & & 0.22 & \\
\hline Random Slopes - Social Trust & 0.001 & & 0.001 & & 0.002 & \\
\hline Random Slopes - Institutional Trust & 0.004 & & 0.002 & & 0.002 & \\
\hline AIC & $1,251,483$ & & 402,553 & & 843,452 & \\
\hline BIC & $1,251,805$ & & 402,839 & & 843,763 & \\
\hline Df & 30 & & 30 & & 30 & \\
\hline Marginal $\mathrm{R}^{2} /$ Conditional $\mathrm{R}^{2}$ & $37.7 \% / 40.5 \%$ & & $31.8 \% / 34.6 \%$ & & $17.7 \% / 67.7 \%$ & \\
\hline
\end{tabular}

After the comparison of different models with different goodness-of-fit indices (AIC, BIC), we included random slopes regarding social and institutional trust in addition to random intercepts. We additionally controlled for time effects by adding random intercepts for every ESS round. All effects are significant on a $p<0.05$ level with exceptions marked as non-significant (ns.)

We observe minor differences using "Happiness" and "Life satisfaction" as outcome variables

All countries: "Suburbs" is significant with "Happiness" as outcome variable

Transition countries: "Lower secondary school" is not significant with "Life satisfaction" as outcome variable, "Upper secondary-"as well as "Post-secondary school" are significant with "Happiness" as outcome variable, "Countryside" is not significant with "Happiness" as well as "Life satisfaction" as outcome variables

Developed countries: "Aggregate institutional trust" is significant with "Happiness" as outcome variable while "Suburbs" is significant with "Life satisfaction" as outcome variable 
varies between countries. The variation regarding social trust is low, coefficients range from 0.06 to 0.21 , whereas 34 of 36 countries (94\%) show an unstandardized beta coefficient between 0.12 and 0.21 . For institutional trust we see more variation: Overall, Nordic and Central European countries tend to show a weaker relation whereas Southern and Eastern European countries show a stronger relation. Specifically, for Denmark, Iceland, Estonia, the Netherlands, Belgium, Finland, Switzerland, Sweden, Norway, Israel, Slovenia, Austria, Poland, Great Britain and Italy, we see a positive relation between institutional trust and subjective well-being ranging from 0.01 to 0.10 . A stronger correlation can be found in the Czech Republic, Portugal, Greece, Estonia, Romania, Russia, Albania, Hungary, Latvia, Turkey, Lithuania, Ukraine and Bulgaria (with unstandardized beta coefficients between 0.14 and 0.24 ). This result is in accordance to the stronger effect of institutional trust on SWB for transition countries since this country group strongly overlaps with Eastern European countries.

As a last step, we analyze the relation between trust and subjective well-being on the aggregate level by using a repeated cross-sectional design. In the first model, we include a dummy variable for transition countries in order to control for differences in SWB between our two country groups. Further, we include our control variables $\log _{2}$ of GDP per capita, inflation, unemployment and income inequality (Gini coefficient). Step by step, we include social trust and institutional trust in our models (see model 3 and 4 in Table 4). At the end, we analyze differences between certain countries as well as between developed and transition countries. ${ }^{5}$ Besides the described control variables, we additionally included a groupmean centered "ESS round" variable as well as it's square in every model to control for linear as well as quadratic time effects. The results are depicted in Table 4.

As we see, SWB is lower in transition countries compared to developed countries. In accordance to the literature, this effect vanishes after including our control variables (see Nikolova 2016, see model 2 to 5 in Table 4). Altogether, our models show a good fit. With our predictor variables, we can explain between $72.5 \%$ (including macroeconomic control variables) and $82.1 \%$ (including control variables and trust) of variance, whereas the full models (including random effects) explain approximately $97 \%$ of variance. Further, we calculated six additional models, each including just one of our six predictor variables (see Table 5). This way we can estimate the unique effects of our variables on SWB. $\log _{2}$ of GDP, social trust and institutional trust show the strongest effects on SWB by explaining around $65 \%$ of variance each. Unemployment, inflation and income inequality (Gini) show a noticeable smaller effect by explaining $20-34 \%$ of variance. $^{6}$

Despite this positive effect of economic growth ( $\log _{2}$ of GDP growth) on subjective well-being (see Table 5), this relation vanishes and becomes insignificant after including the remaining control variables (Table 4, model 2-5). For a better understanding, we run the model again by first including $\log _{2}$ of GDP and afterwards unemployment, inflation or the Gini coefficient to our model (results upon request from the authors). This analysis indicates that unemployment is the key mediating variable which leads to this vanished effect of economic growth on subjective well-being. Further, we see that countries with a higher $\log _{2}$ of GDP report higher subjective well-being, and that a $1 \%$ decrease in unemployment

\footnotetext{
5 Separate analysis for developed and transition countries are depicted in Table A4 in the supplementary material.

6 We additionally analyzed the effect of corruption, but excluded this variable due to a high correlation with GDP per capita. However, the effect of the Corruption Perception Index by means of data from Transparency International on SWB explained $74 \%$ of the variance.
} 


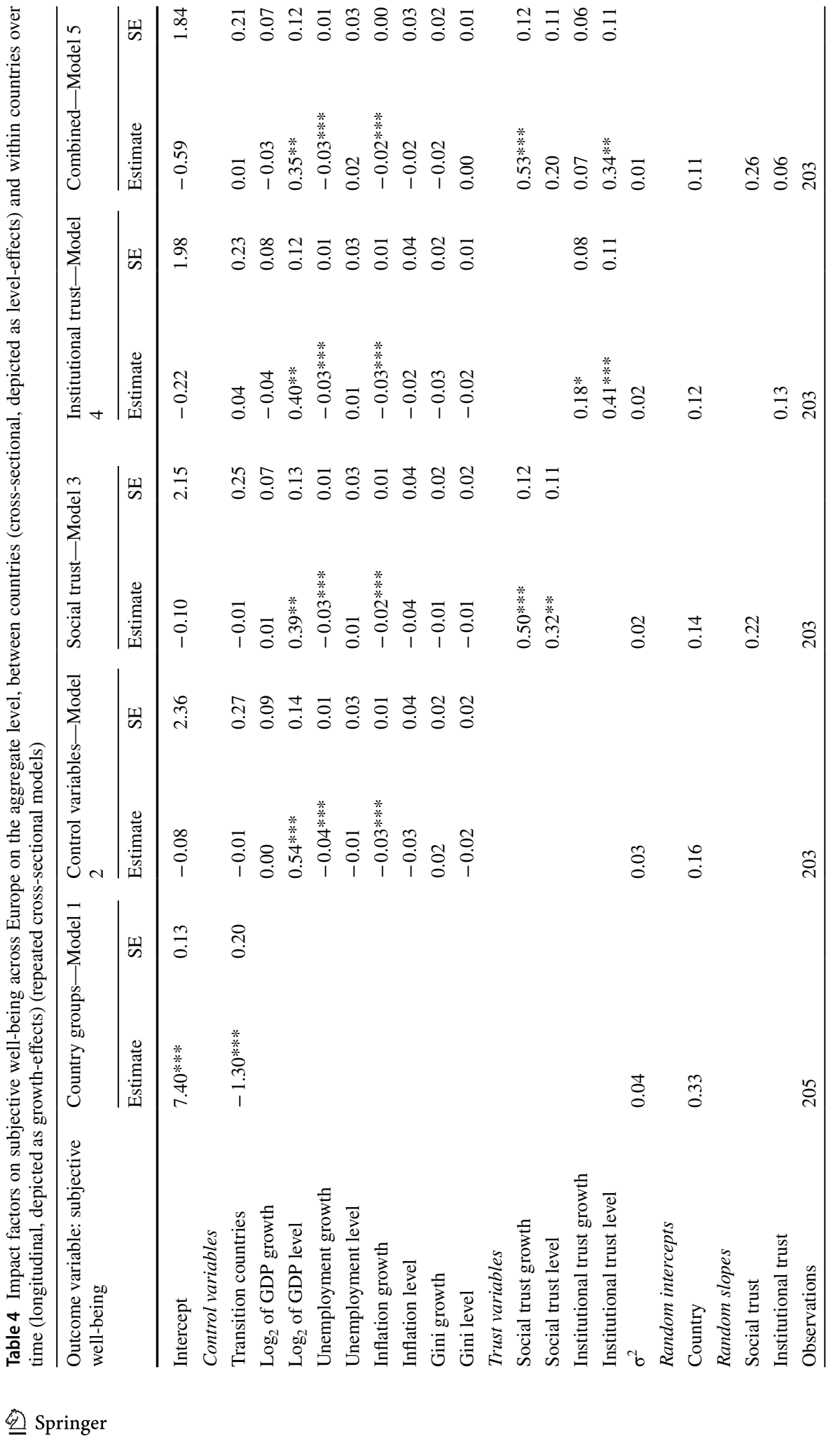




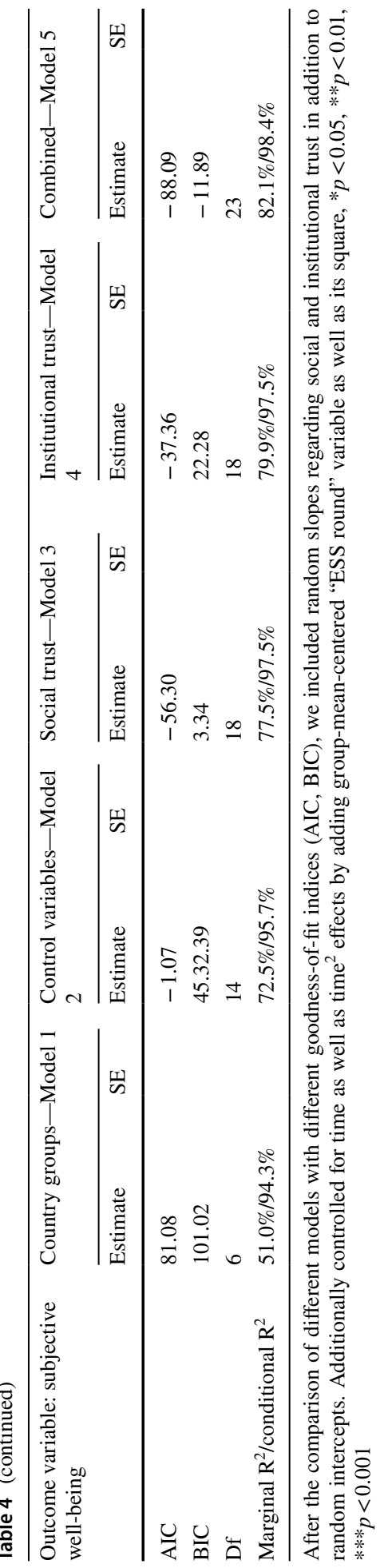




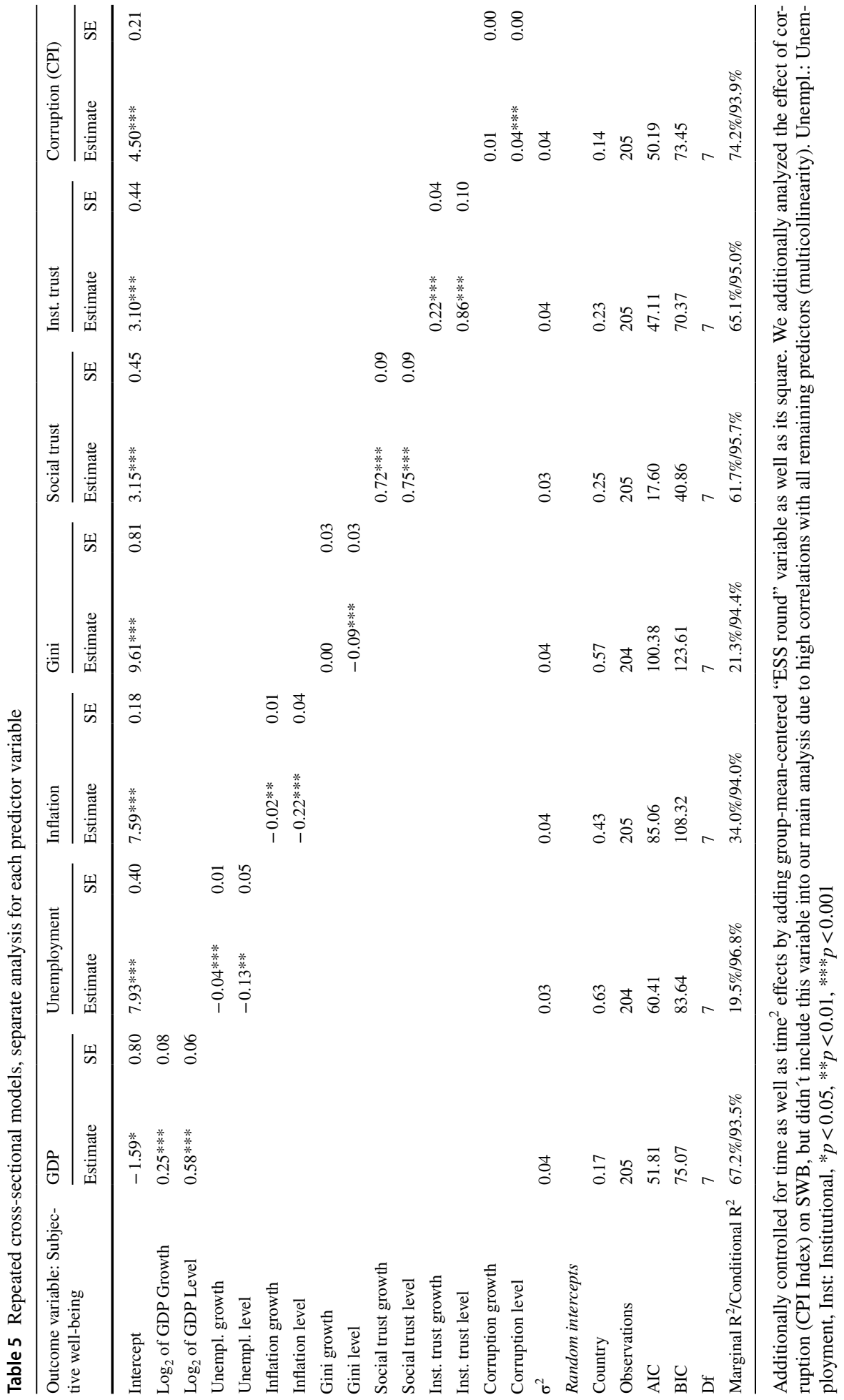


(and inflation) leads to an increase of $0.04(0.03)$ points in aggregate subjective well-being (scale: $0-10)$ over and above economic growth, income inequality, social trust and institutional trust. Income inequality on the other hand, measured by the Gini coefficient, is not related to SWB. This is in accordance to previous literature (Di Tella et al. 2001; Lopes et al. 2014; Ngamaba et al. 2018).

Regarding trust, we see that both growth-(within) and level-(between) effects of social as well as institutional trust foster SWB. After we include both trust variables in model 5, we see that only the growth effect of social trust and the level effect of institutional trust remain significant. An increase of aggregate social trust by one point leads to an increase in aggregate subjective well-being of 0.53 points over time. Increasing institutional trust by one point, on the other hand, shows only a small, non-significant impact on aggregate subjective well-being by an increase of 0.07 points. Therefore, increasing social trust leads to an increase in SWB over time while an increase in institutional trust does not affect SWB. Individuals who live in countries with a high level of institutional trust on the other hand report higher levels in SWB. These findings shed light on previously reported ambiguous relations between institutional trust and SWB (Bartolini et al. 2013a; Kroll 2008). Our analyses show a cross-sectional relation between institutional trust and SWB on the individual and the aggregate level, but no relation over time on the aggregate level. This implies that omitted confounding variables are the reason for the cross-sectional relations, while institutional trust ceteris paribus does not affect SWB.

After we reported the general findings above, we will now move to differences between single countries and country groups. First, we used interaction terms to examine differences between developed and transition countries but only detected one significant effect. While economic growth does not affect SWB in transition countries (unstandardized beta coefficient: -0.02 , ns.), it shows a small negative effect on SWB in developed countries (unstandardized beta coefficient: $-0.18, p<0.05$ ). Since the relation between the change in social trust (within effect) and SWB substantially varies between countries as depicted by the random slopes, we took a closer look at this relation for each country. Croatia is the only country with a significantly lower effect of social trust growth on SWB with a negative unstandardized beta coefficient $(-0.18)$. Italy, Turkey and Portugal on the other hand show a significantly and substantially higher effect with unstandardized beta coefficients around 1.40 .

\section{Discussion and Conclusion}

The aim of this paper was to replicate and extent previous research about the relation between social and institutional trust and subjective well-being. Overall, we analyzed how trust and SWB developed in Europe from 2002 to 2016 and investigated the effect of trust on SWB-on the cross-sectional individual and aggregate level as well as over time. We used the European Social Survey (ESS) to answer these research questions, consisting of survey responses from over 390,000 individuals nested in 36 countries within eight time points.

Over and above the impact of trust and in accordance with previous studies, we found a positive effect of decreasing unemployment and inflation on SWB on the aggregate level. Therefore, our study confirms previous cross-sectional studies (Di Tella et al. 2001; Lopes et al. 2014) which reported the same positive effects by using longitudinal data. In line with 
previous studies (e.g. Ngamaba et al. 2018), we found no effect of income inequality on SWB. Nevertheless, previous research showed that income inequality has a negative effect on life satisfaction inequality as well as on social trust (Graafland and Lous 2019), which implies that reducing income inequality can be a desirable goal after all (see also Deeming and Jones 2015: 277). Regarding economic growth, the Easterlin-paradoxon states that economic growth only fosters subjective well-being in the short run but not in the long run (10 years or more; Easterlin et al. 2010). Our results are in line with the Easterlinparadoxon since we found a positive effect of economic growth in the short run (2 years) on subjective well-being without the consideration of control variables (see Table 5). After controlling for unemployment, this effect vanished and remained small and insignificant after including the remaining variables into our model. This result is in line with "Okun's Law", a rule of thumb which states that increasing economic growth leads to a decreasing unemployment rate (see Knotek 2007).

Contrary to previous literature (e.g. Mikucka et al. 2017), we found a negative effect of GDP growth on subjective well-being after the inclusion of all control variables for developed countries in Europe. Since this subgroup represents homogeneous affluent countries, this finding indicates not only a diminishing marginal utility of GDP, but rather a negative effect of GDP growth at a certain level. This finding however is exploratory and is not of major interest for our analyses. We thus encourage future research to further investigate the effect of GDP growth on SWB in prosperous countries by using recent longitudinal data and multilevel designs.

Regarding the development of trust and SWB over time, our findings show that social trust as well as subjective well-being slightly increased since 2002 despite high levels in the first place. The lowest level of SWB can be observed in 2008 which indicates a temporary consequence of the worldwide economic crisis that, however, did not influence the European's trust. A close look on the four countries which were most affected by the economic crisis in terms of SWB loss (see Alessi et al. 2018) also shows that only one of those countries faced a small decrease in social trust. However, all four countries suffered from a moderate loss in institutional trust during this period. Overall, our data tentatively suggests that countries which were more affected by the economic crisis (e.g. Greece, Latvia, Croatia, Spain, Portugal) show a decline in institutional trust while less affected countries (e.g. Norway, Sweden, Switzerland, Germany) show no decline or even an increase in institutional trust (see also appendix A2). Overall, our data reveal heterogeneous trends across Europe, particularly in regard of the development of SWB and institutional trust.

In accordance to previous research (e.g. Bjørnskov 2008; Helliwell et al. 2018; Mikucka et al. 2017), we observed a positive effect of social trust on subjective well-being. This positive effect emerged on different levels which all draw a coherent picture. First, we found a positive effect of individual social trust on subjective well-being on the individual cross-sectional level for every participating country. Based on this result, we infer that this effect is independent from country-varying differences, which implies that social trust touches an encompassing basic need fostering social cohesion in modern societies. Second, the country level of social trust (aggregate social trust) fosters individual subjective wellbeing, whereas this effect is particularly stronger than the effect of individual social trust. Thus, living in a trusting environment is particularly beneficial for individual subjective well-being. This finding is also in accordance to our longitudinal repeated cross-sectional design which implies that increasing aggregate social trust leads to an increase in aggregate subjective well-being. This result holds both for developed and transition countries over and above the control variables. Social trust is often considered as a prerequisite for social networks as it fosters social cohesion (Kawachi 2008; Helliwell and Putnam 2004: 
1436). Based on psychological theories like the 'need to belong' theory (Baumeister and Leary 1995), social networks meet innate needs since humans are in fact, i.a. evolutionary justified,- - social beings. With this study, we show that social trust as prerequisite of social cohesion does not only foster well-being on the individual level, but also on the aggregate country level, indicating that a socially trusting society is a happy society.

Regarding institutional trust, we see a different picture. In line with previous research (e.g. Puntscher et al. 2015; Leung et al. 2011), we found a positive effect of institutional trust on subjective well-being on the individual cross-sectional level. This relation however varies between countries, with bigger effect sizes in less prosperous-, and smaller effect sizes in prosperous countries. Opposed to our findings regarding social trust, this implies that the effect of institutional trust on subjective well-being depends on omitted confounding variables due to cultural differences. The longitudinal analysis supports this finding by showing a cross-sectional, but no longitudinal relation on the aggregate level. Since less affluent, formerly socialist countries show a stronger relation, low institutional trust could be associated with a general climate of political distrust which could be the reason for this cross-sectional spurious relation. However, more research is needed to fully understand the underlying mechanisms behind the cross-sectional relation between institutional trust and subjective well-being.

By interpreting our results, we have to take certain restriction into account. First of all, our statistical analysis does not allow to derive causality. Thus, besides the theoretical background, we cannot tell for sure if social trust fosters subjective well-being or the other way round. Second, this analysis relies on a homogeneous sample of European countries and Israel. Thus, our results have restricted generalizability for further countries since differences regarding macroeconomic structures could alter these relations. Moreover, regarding the development of trust and SWB over time, we only analyzed countries with at least seven time-points, resulting in a sample with prosperous countries overrepresented.

In sum, our results indicate that an increase in social trust within countries over time leads to higher subjective well-being. Thus, social trust seems to be crucial for Europe's well-being and should be considered as an important indicator for social policy besides GDP per capita, inflation and unemployment. Despite the negligible (nil) effect of economic growth on subjective well-being in the long run (see Easterlin et al. 2010), its positive effect in the short run seems to be moderated by decreasing unemployment. Thus, our data suggests that additional policies to lower unemployment could potentially be as beneficial for society's well-being as economic growth. Additionally, decreasing inflation leads to higher subjective well-being as well. High institutional trust on the other hand only affects subjective well-being on the individual and aggregate cross-sectional level but not over time, indicating a spurious effect created by omitted confounding variables.

\subsection{Future Research}

Although our results show a strong relation between social trust and SWB, we are not able to infer a causal pathway. Thus, we suggest that future research should analyze the causality between social trust and SWB. While previous studies used instrumental variables for this manner (see Koruki 2011; Growiec and Growiec 2014), this approach is questionable since meaningful instrumental variables which show a substantial correlation with the predictor of interest are hard to find (see Bound et al. 1995). We thus encourage future research to further analyze the causal effect of social trust on SWB by using longitudinal data with granger-causality or cross-lagged-panel-data designs. One 
step further, we encourage researchers to analyze how to increase social trust, both on the individual and aggregate level. Since our results imply that the cross-sectional relation between institutional trust and SWB is due to omitted confounding variables, future research needs to investigate the underlying mechanism behind this relation. In regard of the explored country differences, we further advice to conduct more sensitive analysis to examine necessary and sufficient conditions for a happy life across Europe, for example via qualitative comparative analysis (Schneider and Wagemann 2007).

Acknowledgements Open access funding provided by University of Graz.

Open Access This article is distributed under the terms of the Creative Commons Attribution 4.0 International License (http://creativecommons.org/licenses/by/4.0/), which permits unrestricted use, distribution, and reproduction in any medium, provided you give appropriate credit to the original author(s) and the source, provide a link to the Creative Commons license, and indicate if changes were made.

\section{References}

Alessi, L., Benczur, P., Campolongo, F., Cariboni, J., Manca, A. R., Menyhert, B., \& Pagano, A. (2018). The resilience of EU Member States to the financial and economic crisis. What are the characteristics of resilient behaviour? (No. JRC111606). Joint Research Centre (Seville site).

Bartolini, S., Bilancini, E., \& Pugno, M. (2013a). Did the decline in social connections depress Americans' happiness? Social Indicators Research, 110(3), 1033-1059. https://doi.org/10.1007/s1120 5-011-9971-X.

Bartolini, S., Bilancini, E., \& Sarracino, F. (2013b). Predicting the trend of well-being in Germany: How much do comparisons, adaptation and sociability matter? Social Indicators Research, 114(2), 169-191.

Bartolini, S., Mikucka, M., \& Sarracino, F. (2017). Money, trust and happiness in transition countries: Evidence from time series. Social Indicators Research, 130(1), 87-106. https://doi.org/10.1007/s1120 5-015-1130-3.

Bartolini, S., \& Sarracino, F. (2014). Happy for how long? How social capital and economic growth relate to happiness over time. Ecological Economics, 108, 242-256. https://doi.org/10.1016/j.ecole con.2014.10.004.

Bartolini, S., \& Sarracino, F. (2015). The dark side of Chinese growth: Declining social capital and wellbeing in times of economic boom. World Development, 74, 333-351. https://doi.org/10.1016/j.world dev.2015.05.010.

Baumeister, R. F., \& Leary, M. R. (1995). The need to belong: Desire for interpersonal attachments as a fundamental human motivation. Psychological Bulletin, 117(3), 497-529. https://doi. org/10.1037/0033-2909.117.3.497.

Bell, A., \& Jones, K. (2015). Explaining fixed effects: Random effects modeling of time-series crosssectional and panel data. Political Science Research and Methods, 3(01), 133-153. https://doi. org/10.1017/psrm.2014.7.

Bell, A., Jones, K., \& Fairbrother, M. (2018). Understanding and misunderstanding group mean centering: A commentary on Kelley et al.'s dangerous practice. Quality \& Quantity, 52(5), 2031-2036. https:// doi.org/10.1007/s11135-017-0593-5.

Benz, A. (2002). Vertrauensbildung in Mehrebenensystemen. In R. Schmalz-Bruns \& Z. Reinhard (Eds.), Politisches vertrauen. Soziale grundlagen reflexiver kooperation (pp. 275-291). Nomos: Baden-Baden.

Bjørnskov, C. (2008). Social capital and happiness in the United States. Applied Research in Quality of Life, 3(1), 43-62. https://doi.org/10.1007/s11482-008-9046-6.

Bjørnskov, C., \& Sønderskov, K. M. (2013). Is social capital a good concept? Social Indicators Research, 114(3), 1225-1242. https://doi.org/10.1007/s11205-012-0199-1.

Bound, J., Jaeger, D. A., \& Baker, R. M. (1995). Problems with instrumental variables estimation when the correlation between the instruments and the endogenous explanatory variable is weak. Journal of the American statistical association, 90(430), 443-450.

Bourdieu, P. (1986). The forms of capital. In J. G. Richardson (Ed.), Handbook of theory and research for the sociology of education (pp. 241-258). New York: Greenwood. 
Bünger, B. (2010). The demand for relational goods: empirical evidence from the European Social Survey. International Review of Economics, 57(2), 177-198. https://doi.org/10.1007/s12232-010-0094-5.

Calvo, R., Zheng, Y., Kumar, S., Olgiati, A., \& Berkman, L. (2012). Well-being and social capital on planet earth: Cross-national evidence from 142 countries. PLOS ONE, 7(8), e42793. https://doi.org/10.1371/ journal.pone.0042793.

Coleman, J. S. (2000). Foundations of social theory (3. print.). Cambridge: Belknap Press of Harvard Univ. Press.

Dalton, R. J., \& Weldon, S. A. (2005). Public images of political parties: A necessary evil? West European Politics, 28(5), 931-951. https://doi.org/10.1080/01402380500310527.

Deeming, C., \& Jones, K. (2015). Investigating the macro determinants of self-rated health and well-being using the European social survey: Methodological innovations across countries and time. International Journal of Sociology, 45(4), 256-285.

Di Tella, R., MacCulloch, R. J., \& Oswald, A. J. (2001). Preferences over inflation and unemployment: Evidence from surveys of happiness. American Economic Review, 91(1), 335-341. https://doi. org/10.1257/aer.91.1.335.

Diener, E., Oishi, S., \& Lucas, R. E. (2012). Subjective well-being: The science of happiness and life satisfaction. In S. J. Lopez, \& C. R. Snyder (Eds.), (Vol. 1). Oxford: Oxford University Press. https://doi. org/10.1093/oxfordhb/9780195187243.013.0017.

Diener, E., Oishi, S., \& Lucas, R. E. (2015). National accounts of subjective well-being. American Psychologist, 70(3), 234-242. https://doi.org/10.1037/a0038899.

Diener, E., \& Ryan, K. (2009). Subjective well-being: A general overview. South African Journal of Psychology, 39(4), 391-406. https://doi.org/10.1177/008124630903900402.

Dolan, P., Peasgood, T., \& White, M. (2008). Do we really know what makes us happy? A review of the economic literature on the factors associated with subjective well-being. Journal of Economic Psychology, 29(1), 94-122. https://doi.org/10.1016/j.joep.2007.09.001.

Easterlin, R. A. (1974). Does economic growth improve the human lot? Some empirical evidence. In Nations and households in economic growth (pp. 89-125). Elsevier. https://doi.org/10.1016/b978-012-205050-3.50008-7.

Easterlin, R. A., McVey, L. A., Switek, M., Sawangfa, O., \& Zweig, J. S. (2010). The happiness-income paradox revisited. Proceedings of the National Academy of Sciences, 107(52), 22463-22468. https:// doi.org/10.1073/pnas.1015962107.

Fairbrother, M. (2014). Two multilevel modeling techniques for analyzing comparative longitudinal survey datasets. Political Science Research and Methods, 2(01), 119-140. https://doi.org/10.1017/ psrm.2013.24.

Graafland, J., \& Lous, B. (2019). Income inequality, life satisfaction inequality and trust: A cross country panel analysis. Journal of Happiness Studies, 20(6), 1717-1737.

Growiec, K., \& Growiec, J. (2014). Trusting only whom you know, knowing only whom you trust: The joint impact of social capital and trust on happiness in CEE countries. Journal of Happiness Studies, 15(5), 1015-1040.

Hawkins, D. M. (2004). The problem of overfitting. Journal of Chemical Information and Computer Sciences, 44(1), 1-12. https://doi.org/10.1021/ci0342472.

Helliwell, J. F., \& Huang, H. (2011). Well-being and trust in the workplace. Journal of Happiness Studies, 12(5), 747-767.

Helliwell, J. F., Huang, H., \& Wang, S. (2018). New evidence on trust and well-being (p. 409). Oxford: The Oxford Handbook of Social and Political Trust.

Helliwell, J. F., \& Putnam, R. D. (2004). The social context of well-being. Philosophical Transactions of the Royal Society B: Biological Sciences, 359(1449), 1435-1446. https://doi.org/10.1098/rstb.2004.1522.

Hooghe, M., \& Vanhoutte, B. (2011). Subjective well-being and social capital in Belgian communities. The impact of community characteristics on subjective well-being indicators in Belgium. Social Indicators Research, 100(1), 17-36. https://doi.org/10.1007/s11205-010-9600-0.

Howell, R. T., \& Howell, C. J. (2008). The relation of economic status to subjective well-being in developing countries: A meta-analysis. Psychological Bulletin, 134(4), 536-560. https://doi. org/10.1037/0033-2909.134.4.536.

Hox, J. J., Moerbeek, M., \& van de Schoot, R. (2017). Multilevel analysis: Techniques and applications (3rd ed.). New York: Routledge. https://doi.org/10.4324/9781315650982.

Hudson, J. (2006). Institutional trust and subjective well-being across the EU. Kyklos, 59(1), 43-62. https:// doi.org/10.1111/j.1467-6435.2006.00319.x.

Kawachi, I. (Ed.). (2008). Social capital and health. New York: Springer.

Knotek, E. S., II. (2007). How useful is Okun's law? Economic Review-Federal Reserve Bank of Kansas City, 92(4), 73. 
Kroll, C. (2008). Social capital and the happiness of nations: The importance of trust and networks for life satisfaction in a cross-national perspective. Frankfurt: P. Lang.

Kuroki, M. (2011). Does social trust increase individual happiness in Japan? The Japanese Economic Review, 62(4), 444-459.

Leung, A., Kier, C., Fung, T., Fung, L., \& Sproule, R. (2011). Searching for happiness: The importance of social capital. Journal of Happiness Studies, 12(3), 443-462. https://doi.org/10.1007/s1090 2-010-9208-8.

Lopes, H., Calapez, T., \& Porto, C. (2014). Does the macroeconomic context influence subjective wellbeing in Europe and Portugal? The puzzling case of the 2008 crisis. Portuguese Journal of Social Science, 13(1), 3-19. https://doi.org/10.1386/pjss.13.1.3_1.

Macchia, L., \& Plagnol, A. C. (2018). Life satisfaction and confidence in National Institutions: Evidence from South America. Applied Research in Quality of Life. https://doi.org/10.1007/s11482-018-9606-3.

Mikucka, M., Sarracino, F., \& Dubrow, J. K. (2017). When does economic growth improve life satisfaction? Multilevel analysis of the roles of social trust and income inequality in 46 countries, 1981-2012. World Development, 93, 447-459. https://doi.org/10.1016/j.worlddev.2017.01.002.

Mirman, D. (2014). Growth curve analysis and visualization using R. Boca Raton: CRC Press/Taylor \& Francis Group.

Mironova, A. A. (2015). Trust, social capital, and subjective individual well-being. Sociological Research, 54(2), 121-133. https://doi.org/10.1080/10610154.2015.1082391.

Mishler, W., \& Rose, R. (2001). What are the origins of political trust?: Testing institutional and cultural theories in post-communist societies. Comparative Political Studies, 34(1), 30-62. https://doi. org/10.1177/0010414001034001002.

Nakagawa, S., \& Schielzeth, H. (2013). A general and simple method for obtaining $R^{2}$ from generalized linear mixed-effects models. Methods in Ecology and Evolution, 4(2), 133-142. https://doi.org/10.1111/ j.2041-210x.2012.00261.x.

Ngamaba, K. H., Panagioti, M., \& Armitage, C. J. (2018). Income inequality and subjective well-being: A systematic review and meta-analysis. Quality of Life Research, 27(3), 577-596. https://doi. org/10.1007/s11136-017-1719-x.

Nikolova, M. (2016). Minding the happiness gap: Political institutions and perceived quality of life in transition. European Journal of Political Economy, 45, 129-148. https://doi.org/10.1016/j.ejpol eco.2016.07.008.

Oishi, S., \& Schimmack, U. (2010). Culture and well-being: A new inquiry into the psychological wealth of nations. Perspectives on Psychological Science, 5(4), 463-471. https://doi.org/10.1177/1745691610 375561.

Ortíz-Ospina, E., \& Roser, M. (2017). Happiness and life satisfaction. Published online at https://ourwo rldindata.org/happiness-and-life-satisfaction/. Retrieved May 13, 2019.

Portela, M., Neira, I., \& del Salinas-Jiménez, M. (2013). Social capital and subjective wellbeing in Europe: A new approach on social capital. Social Indicators Research, 114(2), 493-511.

Puntscher, S., Hauser, C., Walde, J., \& Tappeiner, G. (2015). The impact of social capital on subjective well-being: A regional perspective. Journal of Happiness Studies, 16(5), 1231-1246. https://doi. org/10.1007/s10902-014-9555-y.

Putnam, R. D. (2001). Bowling alone: The collapse and revival of American community (1 touchstone ed.). New York: Simon \& Schuster.

Rodríguez-Pose, A., \& von Berlepsch, V. (2014). Social capital and individual happiness in Europe. Journal of Happiness Studies, 15(2), 357-386. https://doi.org/10.1007/s10902-013-9426-y.

Sarracino, F. (2010). Social capital and subjective well-being trends: Comparing 11 western European countries. The Journal of Socio-Economics, 39(4), 482-517. https://doi.org/10.1016/j.socec.2009.10.010.

Sarracino, F. (2012). Money, sociability and happiness: Are developed countries doomed to social erosion and unhappiness?: Time-series analysis of social capital and subjective well-being in western Europe, Australia, Canada and Japan. Social Indicators Research, 109(2), 135-188. https://doi.org/10.1007/ s11205-011-9898-2.

Sarracino, F. (2014). Richer in money, poorer in relationships and unhappy? Time series comparisons of social capital and well-being in Luxembourg. Social Indicators Research, 115(2), 561-622. https://doi. org/10.1007/s11205-012-0223-5.

Sarracino, F., \& Mikucka, M. (2017). Social capital in Europe from 1990 to 2012: Trends and convergence. Social Indicators Research, 131(1), 407-432. https://doi.org/10.1007/s11205-016-1255-z.

Schneider, C. Q., \& Wagemann, C. (2007). Qualitative comparative analysis und fuzzy sets: Ein Lehrbuch für Anwender und jene, die es werden wollen. Opladen: Budrich.

Schwadel, P., \& Stout, M. (2012). Age, period and cohort effects on social capital. Social Forces, 91(1), 233-252. https://doi.org/10.1093/sf/sos062. 
Solt, F. (2019) Measuring income inequality across countries and over time: The standardized world income inequality database. SWIID Version 8.0.

Twenge, J. M., Campbell, W. K., \& Carter, N. T. (2014). Declines in trust in others and confidence in institutions among American adults and late adolescents, 1972-2012. Psychological Science, 25(10), 1914-1923. https://doi.org/10.1177/0956797614545133.

van Oorschot, W., \& Arts, W. (2005). The social capital of European welfare states: the crowding out hypothesis revisited. Journal of European Social Policy, 15(1), 5-26. https://doi.org/10.1177/09589 28705049159.

Veenhoven, R. (2014). Long-term change of happiness in nations. In Stability of Happiness (pp. 167-200). Elsevier. https://doi.org/10.1016/b978-0-12-411478-4.00009-6.

Warren, M. E. (1999). Democracy and trust. Cambridge: Cambridge University Press.

Publisher's Note Springer Nature remains neutral with regard to jurisdictional claims in published maps and institutional affiliations. 